\title{
Control of Myelination by Specific Patterns of Neural Impulses
}

\author{
Beth Stevens, ${ }^{1}$ Sandra Tanner, ${ }^{2}$ and R. Douglas Fields ${ }^{1}$ \\ ${ }^{1}$ National Institute of Child Health and Human Development, Laboratory of Developmental Neurobiology, and ${ }^{2} \mathrm{National}$ \\ Institute of Neurological Disorders and Stroke, Laboratory of Molecular and Cellular Neurobiology, National Institutes of \\ Health, Bethesda, Maryland 20892
}

A cell culture preparation equipped with stimulating electrodes was used to investigate whether action potential activity can influence myelination of mouse dorsal root ganglia axons by Schwann cells. Myelination was reduced to one-third of normal by low-frequency impulse activity $(0.1 \mathrm{~Hz})$, but higherfrequency stimulation $(1 \mathrm{~Hz})$ had no effect. The number of Schwann cells and the ultrastructure of compact myelin were not affected. The frequency of stimulation that inhibited myelination decreased expression of the cell adhesion molecule L1,

Nervous system function in vertebrates is critically dependent on the formation of myelin sheaths surrounding central and peripheral axons during the perinatal period. The molecular signals inducing myelination are not known, but initiation of myelination requires contact with membrane-bound molecules on the axon (Wood and Bunge, 1975; Salzer et al., 1980), and myelination is regulated precisely according to the diameter and conduction properties of the axon (Duncan, 1934; Aguayo et al., 1976). A number of signals and processes are probably critical in controlling the interaction between myelinating Schwann cells and axons during development, but functional activity might provide an important influence.

There are major differences in axon firing patterns during myelinating and premyelinating periods of dorsal root ganglia (DRG) development (Fields, 1998). Spontaneous impulse activity begins in DRG neurons when their axon terminals reach the periphery, even before they form functional end organs or synaptic connections with the CNS (Fitzgerald, 1987; Fitzgerald and Fulton, 1992). The significance of prenatal impulse activity is unknown, because DRG neurons are not spontaneously active postnatally. Initially the frequency of impulse activity is slow $(<0.5 \mathrm{~Hz})$, but the rate of firing increases with later stages of development [1-10 Hz at embryonic day 19 (E19)] (Fitzgerald and Fulton, 1992). Although Schwann cells are closely associated with DRG axons when they are firing at low frequency, myelination does not begin until the prenatal period when the firing pattern increases to a higher frequency (Fitzgerald and Fulton, 1992). The present experiments test whether myelination is inhibited by a frequency of axonal firing characteristic of firing patterns before the onset of myelination.

\footnotetext{
Received Jan. 28, 1998; revised Aug. 17, 1998; accepted Aug. 26, 1998.

We thank Melitta Schachner, Richard Quarles, Vittorio Gallo, George Bittner, Gordon Guroff, and P.J.H. for constructive criticisms of this manuscript.

Correspondence should be addressed to Dr. R. Douglas Fields, Head, Neurocytology and Physiology Unit, National Institutes of Health, National Institute of Child Health and Human Development, Laboratory of Developmental Neurobiology, 49 Convent Drive, Building 49, Room 5A38, Bethesda, MD 20892.

Copyright (C) 1998 Society for Neuroscience $\quad 0270-6474 / 98 / 189303-09 \$ 05.00 / 0$
}

and stimulation under conditions that prevented the reduction in L1 blocked the effects on myelination. This link between myelination and functional activity in the axon at specific frequencies that change axonal expression of L1 could have important consequences for the structural and functional relationship of myelinating axons.

Key words: myelination; impulse activity; L1; DRG neuron; Schwann cell; cell adhesion molecule

The involvement of impulse activity in myelination by Schwann cells has not been examined previously, but it has been suggested that impulse activity could be a necessary stimulus for inducing myelination in the CNS (Demerens et al., 1996). However, results of experiments on this question are controversial and open to alternative interpretations (Collelo et al., 1995; Shrager and Novakovic, 1995). Pharmacological methods of manipulating impulse activity could also affect ion channels in glia, which are known to influence proliferation and myelination, and proliferation of oligodendrocyte progenitor cells is influenced by the activity-dependent release of trophic factors (Barres and Raff, 1993). Differences in myelination could result from changes in the number of oligodendrocytes, rather than from a direct effect on the myelination process.

The molecular mechanisms whereby axonal firing might regulate myelination are unknown. Recent results have shown that expression of calcium-dependent (Itoh et al., 1997) and calciumindependent (Itoh et al., 1995b) cell adhesion molecules (CAMs) is regulated by specific frequencies of firing in DRG neurons. One of these cell adhesion molecules, L1, has been shown to have a critical role in the initiation phase of myelination in vitro (Seilheimer et al., 1989; Wood et al., 1990). The objective of the present experiments was to determine whether differences in the pattern of axonal firing, resembling those accompanying changes in activity pattern during development, could influence myelination and whether changes in axonal expression of cell adhesion molecules known to control myelination could be involved.

\section{MATERIALS AND METHODS}

Cell culture. Dorsal root ganglia were dissected from E13.5 fetal mice, and neurons were dissociated and cultured in the side compartments (70,000 cells/side) of a multicompartment chamber equipped for electrical stimulation, as described previously (Fields et al., 1992). Neurons were maintained in medium containing 5\% heat-inactivated horse serum (HS) supplemented with $50 \mathrm{ng} / \mathrm{ml}$ nerve growth factor (Collaborative Biomedical Products, Bedford, MA) according to previously published methods (Fields et al., 1990). Mitosis of non-neuronal cells was inhibited by $3-4 \mathrm{~d}$ of treatment with $13 \mu \mathrm{g} / \mathrm{ml}$ fluoro-2'-deoxyuridine beginning $1 \mathrm{~d}$ after plating. These cultures can be maintained indefinitely with half-volume changes of medium every 3-4 d, but they were used after 
3-4 weeks in culture. DRG cultures were free from Schwann cell contamination as detected by RT-PCR for a Schwann cell-specific isoform of L1 (Takeda et al., 1996). Schwann cells were dissociated from the sciatic nerve of $3 \mathrm{~d}$ postnatal mice and cultured by the Brockes method (Kleitman et al., 1991) with slight modifications. Sciatic nerves were incubated for 30 min with $0.1 \%$ collagenase in D1 (Colorado Serum, Denver, CO) at $37^{\circ} \mathrm{C}$. The medium was replaced by $0.25 \%$ trypsin $+0.1 \%$ collagenase and incubated as before. Cells were dissociated and plated on uncoated $60 \mathrm{~mm}$ plastic culture dishes in medium containing $5 \%$ horse serum. The following day, culture medium was replaced with medium containing $10^{-5}$ M cytosine arabinoside (Sigma, St. Louis, MO) to prevent proliferation of non-neuronal cells. Contaminating fibroblasts were eliminated by compliment-mediated lysis during passaging with antibody to Thy1.1 (ATCC, Rockville, MD). These cultures were consistently $>95 \%$ pure Schwann cells based on counts of Schwann cells identified by the O4 antigen.

Electrical stimulation. After 3-4 weeks in culture, DRG neurons were rinsed three times and maintained in NGF-free medium to eliminate the influence of NGF on L1 expression (Itoh et al., 1995b). After $24 \mathrm{hr}$, axons were stimulated for $5 \mathrm{~d}$ at a frequency of 0.1 or $1 \mathrm{~Hz}$ through three platinum electrodes fitted into the lid of the culture dishes (Fields et al., 1992). These cultures are $>70 \%$ large-type DRG neurons as distinguished by the RT97 antibody against phosphorylated neurofilament. Previously published quantitative analysis has shown no change in DRG neuron survival associated with removal of NGF, or stimulation at 0.1 or $1 \mathrm{~Hz}$ (Itoh et al., 1997).

Myelin quantitation. Purified Schwann cells were added to the side compartments $(40,000$ cells/side) of 3- to 4-week-old DRG cultures $1 \mathrm{~d}$ before stimulation for myelination experiments. Five days after coculture ( $4 \mathrm{~d}$ after starting electrical stimulation), Schwann cell differentiation and myelination were initiated by adding $50 \mu \mathrm{g} / \mathrm{ml}$ ascorbic acid in medium containing $10 \%$ horse serum. Myelin profiles were evident by phase-contrast microscopy within 8-10 d of the medium shift and were quantitated in all experiments on day 12-14.

For quantification, compact myelinated profiles were stained with Sudan black or antibody against myelin basic protein (MBP). DRG axons that do not traverse the barrier are not depolarized by the field electrodes (Fields et al., 1992); therefore, myelin profiles were quantified within a $300 \mu \mathrm{m}$ transect adjacent to the central barrier between compartments, to assure that myelination was assessed on axons that had been stimulated. The mean number of myelin profiles in 10 random microscope fields per side compartment was determined, and this value was pooled for statistical analysis by ANOVA from several replicate experiments, where the sample size represented the number of independent cultures (side compartments). The stimulus condition of each dish was unknown to the observer performing the counts. Cultures were then stained with Hoechst nuclear stain so that the number of Schwann cells could be counted.

Adhesion assay. Schwann cells were added to DRG axons that had been stimulated for $5 \mathrm{~d}$ for the acute adhesion assay. The multicompartment insert was removed to expose the uniform monolayer of axons in the region under the barrier. Purified Schwann cells were then added $(200,000 \mathrm{cells} / \mathrm{dish})$ in calcium- and magnesium-free HBSS containing 20 mM HEPES and $3 \mathrm{~mm}$ EGTA to reduce the effects of cadherins and integrins on adhesion, and they were incubated with DRG axons for 0.5 hr at $37^{\circ} \mathrm{C}$. Cultures were then washed twice with constant agitation for $5 \mathrm{~min}$ and fixed with $4 \%$ paraformaldehyde. The mean number of Schwann cells adhering to neurites in each dish was determined from 10 randomly selected microscope fields in the area under the barrier. The results of several dishes were pooled using a statistical analysis by ANOVA based on the mean number of cells in each dish; i.e., $n=$ the number of dishes.

Immunocytochemistry and histochemistry. Co-cultures were fixed with $2 \%$ paraformaldehyde, permeabilized with $0.1 \%$ Triton X-100 in PBS for $10 \mathrm{~min}$, and incubated with monoclonal antibodies against myelin basic protein (Boehringer Mannheim, Indianapolis, IN) at a dilution of 1:500 for $1 \mathrm{hr}$ at room temperature. Primary antibodies were detected with fluorescein-conjugated goat $\mathrm{F}\left(\mathrm{AB}^{\prime}\right) 2$ fragment to mouse IgG (Organon Teknika) at a 1:250 dilution.

Myelin sheaths were also visualized by staining with Sudan black. Co-cultures were fixed overnight at $4{ }^{\circ} \mathrm{C}$ in $4 \%$ paraformaldehyde in $0.1 \mathrm{M}$ sodium phosphate buffer, $\mathrm{pH} 7.4$, and post-fixed in $0.1 \%$ osmium tetroxide for $1 \mathrm{hr}$ at room temperature. After they were dehydrated in a $30-70 \%$ ethanol series, cultures were stained with filtered $0.5 \%$ Sudan black (Sigma) in $70 \%$ ethanol for $1 \mathrm{hr}$.
The co-cultures used in the myelin experiments were counterstained with Hoechst nuclear stain (Molecular Probes, Eugene, OR), at a 1:4000 dilution for $10 \mathrm{~min}$ at room temperature to allow counts of the number of Schwann cells. The nuclear stain provides more discrete localization of Schwann cells for quantitative purposes than a membrane or cytoplasmic stain after the Schwann cells have differentiated into a premyelinating morphology. The Schwann cells stained with antibodies to the $\mathrm{O} 4$ antigen co-localized with $>95 \%$ of all cells stained with the Hoechst nuclear stain. The nuclear morphology of the small number $(<5 \%)$ of contaminating cells was easily distinguished by the large size, asymmetrical shape, and optical plane (on the substratum under the axons). Such nuclei were not counted. The total number of Schwann cell nuclei was determined per field in the area of the culture in which myelinated profiles were quantified, as described above.

Some co-cultures were double-labeled with antibodies against L1 and MBP. After staining for MBP, as described above, cultures were incubated with monoclonal rat antibody against L1 (Boehringer Mannheim) at a 1:20 dilution for $30 \mathrm{~min}$ at room temperature. Rhodamine-labeled goat anti-rat antibody was used at a 1:100 dilution to visualize the L1 antibody (Jackson ImmunoResearch, West Grove, PA). Preparations were examined by confocal microscopy (Bio-Rad, Hercules, CA).

Electron microscopy. Twelve days after the addition of ascorbic acid, co-cultures were rinsed with PBS, fixed in $2.5 \%$ gluteraldehyde in $0.15 \mathrm{M}$

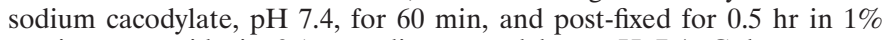
osmium tetroxide in $0.1 \mathrm{M}$ sodium cacodylate, $\mathrm{pH}$ 7.4. Cultures were washed two times in $0.05 \mathrm{M}$ sodium acetate, $\mathrm{pH} 5.0$, and stained with $1 \%$ uranyl acetate in $0.05 \mathrm{M}$ sodium acetate, $\mathrm{pH} 5.0$, for $2 \mathrm{hr}$ at $4^{\circ} \mathrm{C}$. Cultures were then dehydrated through a graded series of ethanol solutions and infiltrated with Epon. After hardening, blocks were cut from side compartments adjacent to the central barrier and mounted on blocks for cross-sectioning. Ultrathin sections were cut with a diamond knife and stained with uranyl acetate and lead citrate and examined by transmission electron microscopy.

RT-PCR. Total RNA was extracted from the side compartments by the method of Chomczynski (Chomczynski and Sacchi, 1987) and reversetranscribed using Superscript RNase H-reverse transcriptase (Life Technologies/BRL, Gaithersburg, MD) according to published methods (Itoh et al., 1997). Synthesized cDNA was amplified in a total volume of $15 \mu \mathrm{l}$ with 0.5 U Amplitaq DNA polymerase (Perkin-Elmer, Branchburg, NJ) in the presence of $0.25 \mathrm{~mm}$ dNTP, $1 \mathrm{mM} \mathrm{MgCl}_{2}$, and $25 \mathrm{pmol}$ of specific primers corresponding to the nucleotides of mouse L1 (3476-3587 and 3611-3587) (Moos et al., 1988) and rat neuron-specific enolase (NSE) (835-855 and 1368-1348) (Sakimura et al., 1985) and cyclophilin (98122, 391-416) (Hasel and Sutcliffe, 1990). Reaction mixtures were amplified for 27-30 cycles, with each cycle consisting of $60 \mathrm{sec}$ denaturation at $95^{\circ} \mathrm{C}, 60 \mathrm{sec}$ annealing at $57^{\circ} \mathrm{C}$ (for L1) and $60^{\circ} \mathrm{C}$ (for NSE and cyclophilin), and $120 \mathrm{sec}$ polymerization at $72^{\circ} \mathrm{C}$. PCR products were analyzed on $6 \%$ polyacrylamide gel and quantified by image densitometry (Universal Imaging, West Chester, PA) after ethidium bromide staining. To correct for variation in cell plating density, expression of L1 was normalized to the expression of NSE, a molecular marker for differentiated neurons, which is not influenced by stimulation at 0.1 or $1 \mathrm{~Hz}$.

Data analysis. All relevant experimental treatments were represented in each experimental set (derived from a single dissection), keeping the number of cultures as balanced as possible. For each statistical comparison, the results of replicate experimental sets were pooled from multiple independent trials from different dissections. Counts were made of cells or myelinated profiles from randomly sampled microscope fields in each preparation, without knowledge of the experimental condition. Results were summarized as the mean for each independent culture preparation (dish or side compartment, depending on the experimental apparatus). This value was entered into the statistical analysis of the aggregate data so that the sample size represented the number of independent experimental trials (not the number of microscope fields). The statistical significance of differences was tested by ANOVA.

\section{RESULTS}

Purified Schwann cells were co-cultured with DRG neurons that had been in culture for 3 weeks (Kleitman et al., 1991). One day later axons were stimulated at a frequency of either 0.1 or $1 \mathrm{~Hz}$ for $5 \mathrm{~d}$ (Fields et al., 1992), and myelination was initiated $5 \mathrm{~d}$ after co-culture by adding ascorbic acid (Eldridge et al., 1987) (Fig. $1 A$ ). Twelve to $14 \mathrm{~d}$ later, compact myelin was detected by Sudan 

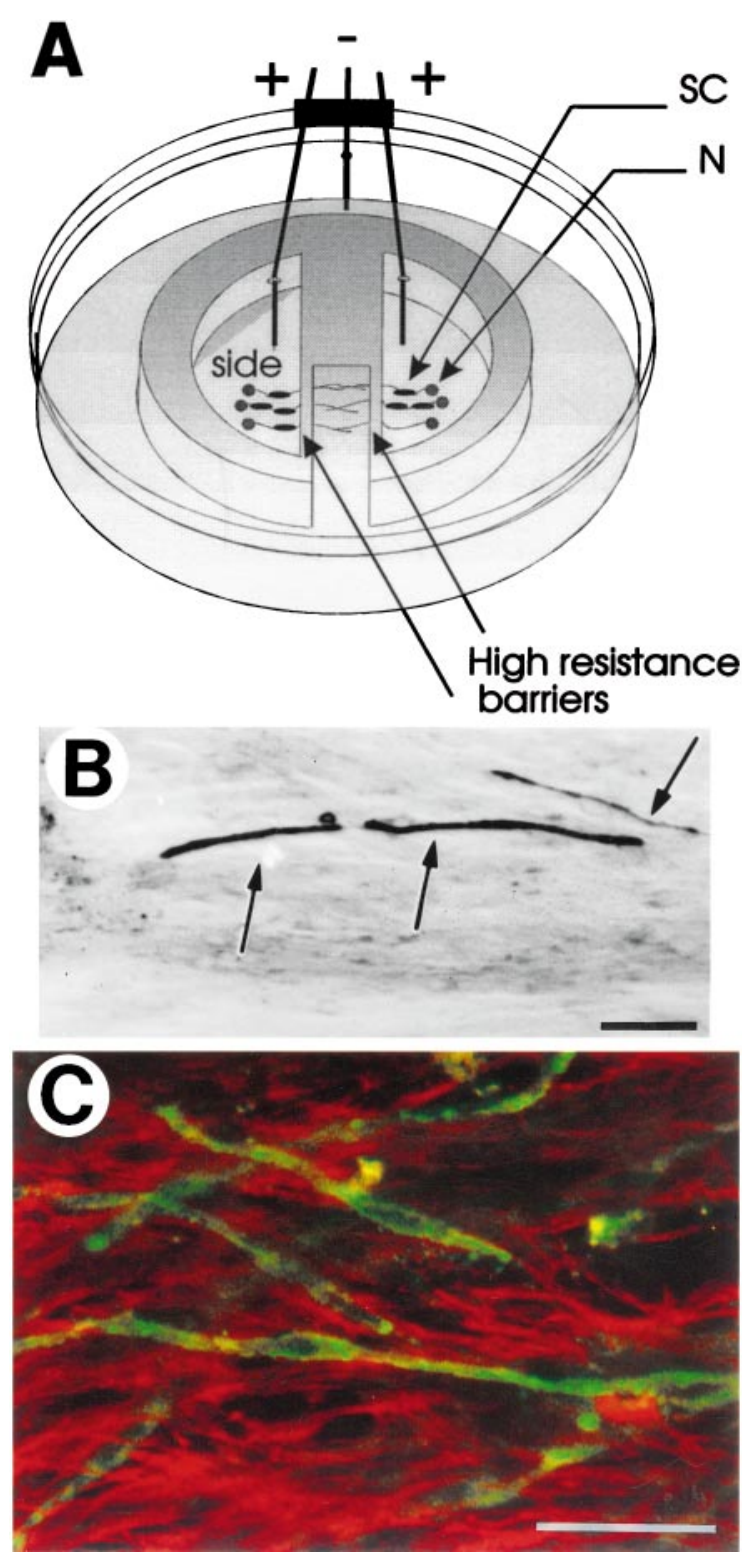

Figure 1. Experimental preparation for studying the effects of action potentials on myelination of DRG neurons in vitro. $A$, Mouse DRG neurons were cultured in the side compartments of multi-compartment cell culture chambers placed in 35-mm-diameter dishes. After 3-4 weeks in culture, axons extend into the central compartment by growing under the high-resistance barriers between compartments. Stimulating electrodes on opposite sides of the barrier were used to control the pattern of action potential firing for up to $5 \mathrm{~d}$ in an incubator. Purified Schwann cells $(S C)$ were added to DRG neuron $(N)$ cultures, and myelination was initiated by the addition of ascorbic acid. B, Compact myelin (arrows) was detected by Sudan black staining or immunocytochemical localization of myelin basic protein (green) (C) 12-14 d after initiating myelination. $C$, Confocal microscopy of preparations double-staining for MBP (green) and L1 (red) shows the disappearance of L1 from the axon and Schwann cell after the fiber becomes myelinated (also see Martini and Schachner, 1986). Scale bars, $50 \mu \mathrm{m}$.

black staining (Fig. 1B) or immunocytochemical detection of MBP (Fig. 1C), and confirmed by electron microscopy (Fig. 2).

The ultrastructure of myelinated profiles was not altered by axonal stimulation, but the number of myelinated profiles in co-cultures was markedly influenced by axonal firing pattern. The morphology of myelinated axons was typical of normal ultrastruc- ture of myelinated axons in co-cultures at a similar stage (Bunge et al., 1989; Carenini et al., 1998) and similar to myelinated axons in the PNS of early postnatal animals (Webster, 1971). The thickness of the myelin sheaths and compaction of the myelin layers appeared similar after stimulation at 0.1 and $1 \mathrm{~Hz}$ (Fig. 2) and in unstimulated controls (data not shown). Compact myelinated profiles were stained by MBP immunocytochemistry and counted (Fig. $3 A, C, E$ ). The number of profiles was significantly reduced ( $p<0.018 ; n=44$ experiments) by more than threefold in cultures that had been stimulated at $0.1 \mathrm{~Hz}$ compared with unstimulated axons or axons stimulated at $1 \mathrm{~Hz}$ (Fig. $3 G$ ). These results were confirmed in experiments using a different method of identifying compact myelin, based on a histochemical stain for lipid (Sudan black). Similar results (threefold reduction) in the number of Sudan black-stained myelin profiles were present in cultures stimulated at $0.1 \mathrm{~Hz}$ compared with unstimulated cultures $(p<0.0001 ; 1.55 \pm 0.15$ vs $0.50 \pm 0.10$ myelin profiles/field for 0 and $0.1 \mathrm{~Hz} ; n=15$ experiments).

Counts of the total number of Schwann cells in these cultures showed no indication that the number of Schwann cells was influenced by stimulation at $0,0.1$ or $1 \mathrm{~Hz}$ (Fig. $3 B, D, F, H)$. This suggests that initiation of myelination is inhibited by axonal firing at low frequency, rather than a secondary reduction in myelination attributable to a decreased number of Schwann cells. Measurements of mitotic rate, using the 5-bromo-2'-deoxyuridine incorporation method, also showed no difference in Schwann cell proliferation rate at the time myelination would be initiated by the addition of ascorbic acid ( $5 \mathrm{~d}$ after plating and after $4 \mathrm{~d}$ of stimulation), regardless of stimulus frequency, and no difference in total number of cells from counts of Schwann cell nuclei stained with Hoechst stain $(1.2 \pm 0.51,1.4 \pm 0.32,1.7 \pm 0.34 \%$ proliferation rates of Schwann cells on axons stimulated at 0, 0.1, and $1 \mathrm{~Hz}$, respectively; $n=18$ experiments). Thus, there is no evidence before or after myelination that differences in Schwann cell numbers could have resulted in differences in myelination.

In contrast to oligodendrocytes, which will synthesize myelin in culture in the absence of neurons (Mirsky et al., 1980), Schwann cells require contact with membrane-bound molecules on axons to initiate the synthesis of myelin (Wood and Bunge, 1975; Salzer et al., 1980). The results suggest that changes in expression of a molecule or molecules on axons firing at $0.1 \mathrm{~Hz}$, but not $1 \mathrm{~Hz}$, may be responsible for inhibiting the induction of myelination by Schwann cells on axons firing at low frequency.

The reduced myelination on axons firing at $0.1 \mathrm{~Hz}$ was associated with a decrease in axonal expression of a calciumindependent cell adhesion molecule. This was shown by stimulating axons for $5 \mathrm{~d}$ at $0.1 \mathrm{~Hz}$ and performing an acute cell adhesion assay using purified Schwann cells. After stimulation, the multicompartment insert (Fig. $1 A$ ) was removed to expose the uniform monolayer of axons in the region under the barrier. Schwann cells were added in calcium- and magnesium-free HBSS to reduce effects of cadherins and integrins on adhesion and incubated with DRG axons for $0.5 \mathrm{hr}$ at $37^{\circ} \mathrm{C}$. After a vigorous wash the number of Schwann cells adhering to the monolayer of DRG axons was reduced by nearly $30 \%$ on axons that had been stimulated at $0.1 \mathrm{~Hz}$ compared with unstimulated controls $(p<$ $0.004 ; 31.0 \pm 1.8$ vs $21.5 \pm 1.7$ cells/field in 0 and $0.1 \mathrm{~Hz}$, respectively; $n=12$ experiments). It is important to note that in the myelination experiments, Schwann cells were added to DRG axons $1 \mathrm{~d}$ before stimulation to preclude possible effects of stimulation on Schwann cell adhesion to DRG axons.

The acute adhesion experiment suggests that downregulation 

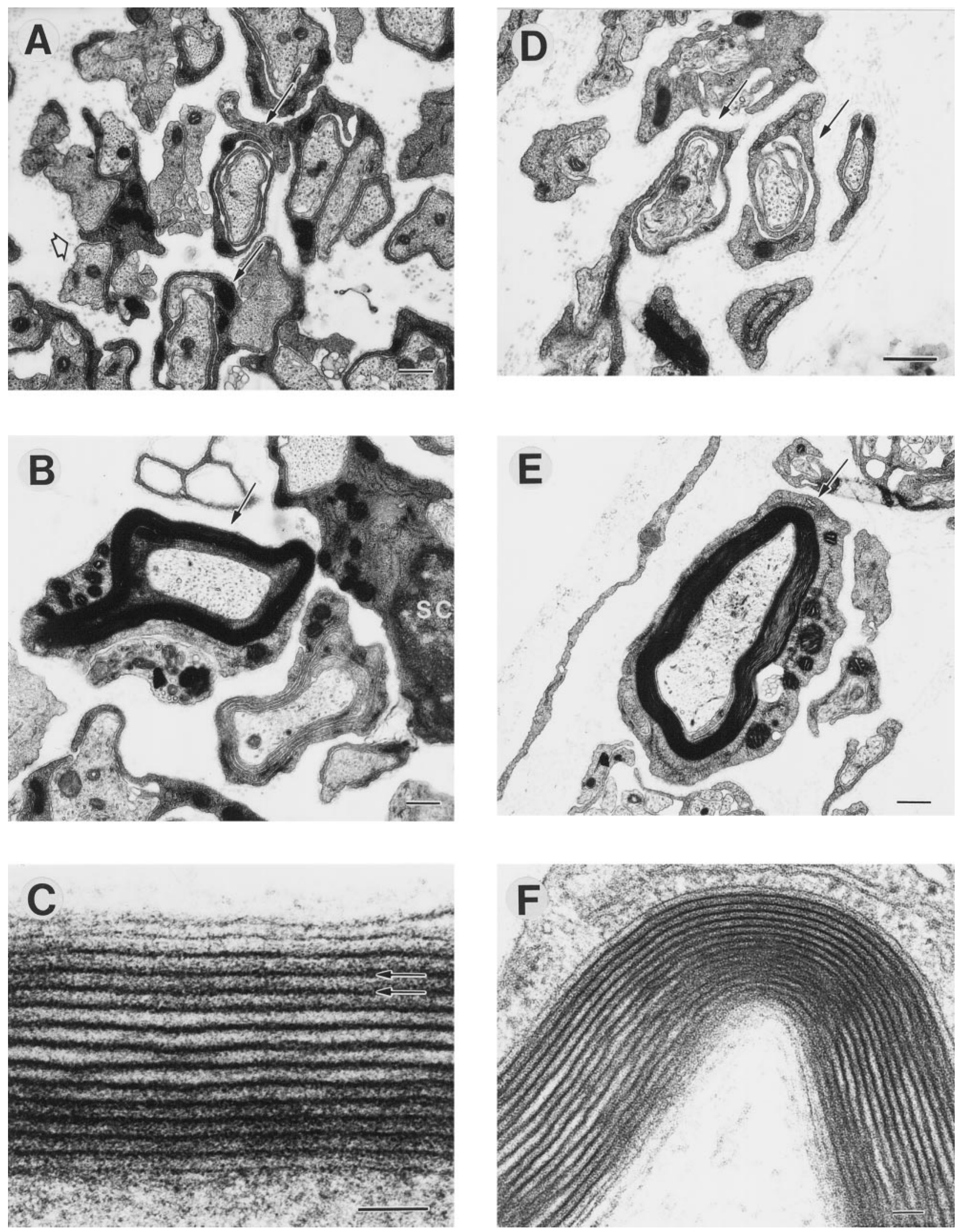

Figure 2. The ultrastructure of myelinated axons was normal in cultures stimulated at $0.1 \mathrm{~Hz}(A-C)$ and $1 \mathrm{~Hz}(D-F)$, and cultures under both stimulus conditions showed axons undergoing several stages of myelination. Note several loose wraps of Schwann cell cytoplasm ensheathing axons $(A, D$, arrows). Higher magnification of a myelinated axon is shown from cultures stimulated at $0.1 \mathrm{~Hz}(C$, arrow) and $1 \mathrm{~Hz}(F$, arrow). Multiple layers (up to 19$)$ of compact myelin, with $\sim 10 \mathrm{~nm}$ between major dense lines $(C$, arrows), were evident in myelinated axons stimulated at $0.1 \mathrm{~Hz}(C)$ and $1 \mathrm{~Hz}(F)$. Scale bars: $A, B, E, 500 \mathrm{~nm} ; C, F, 50 \mathrm{~nm}$. 


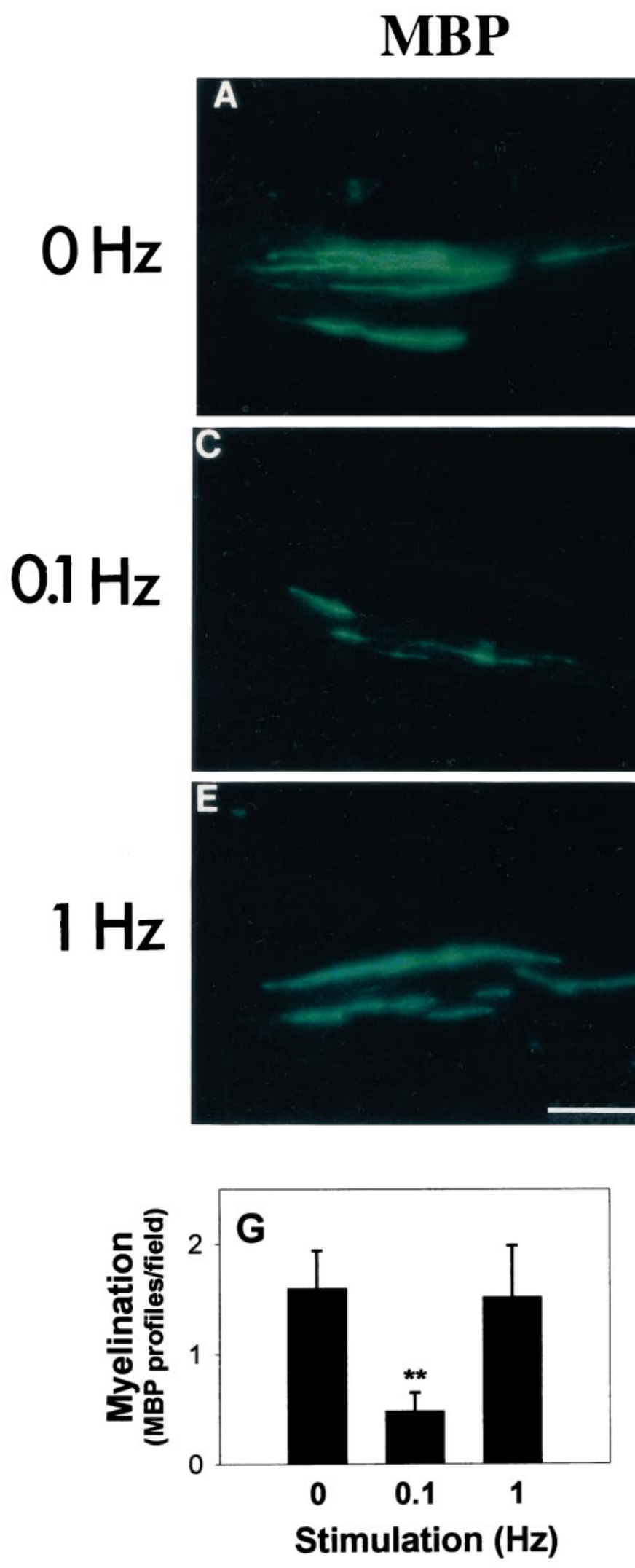

\section{Hoechst}
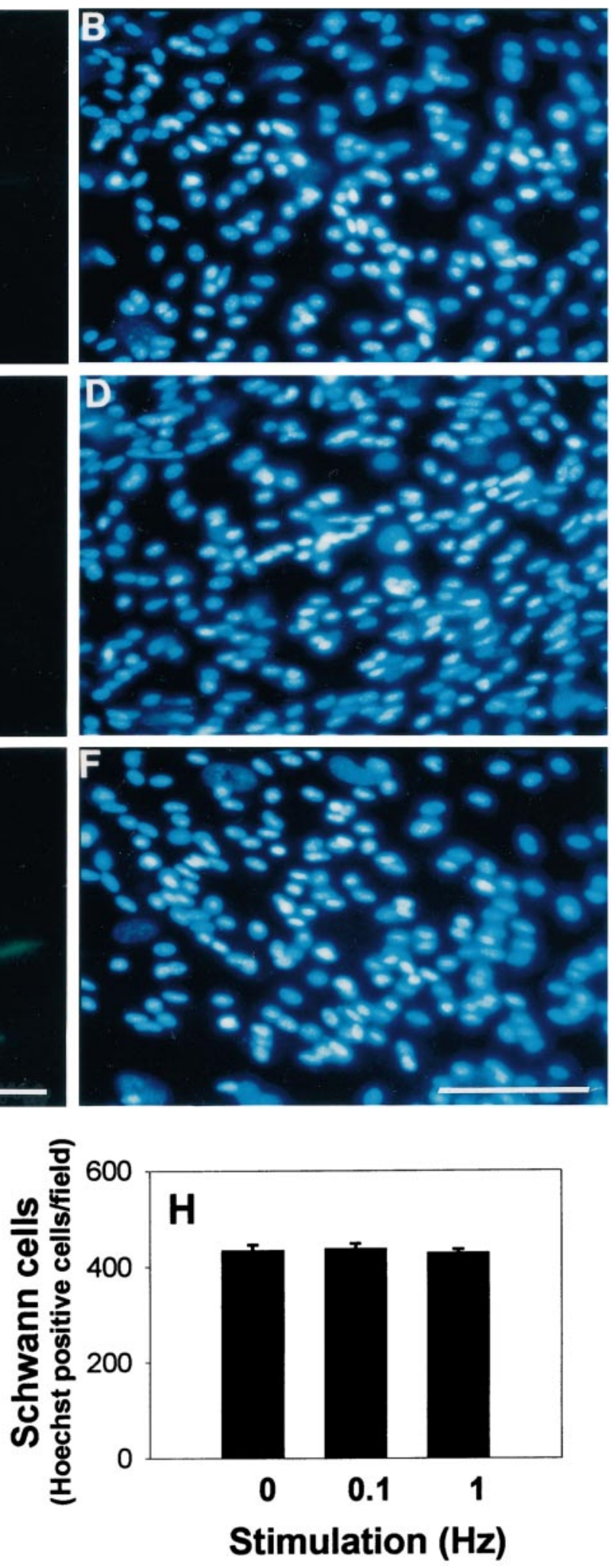

Figure 3. Myelination is inhibited by $0.1 \mathrm{~Hz}$ electrical stimulation. Myelin profiles were identified by immunocytochemical staining for myelin basic protein $(M B P)$ in cultures stimulated at $0(A), 0.1(C)$, and $1(E) \mathrm{Hz}$ for $5 \mathrm{~d}$. Hoechst nuclear stain was used to count the number of Schwann cells in each preparation $(B, D, F)$. $G$, The number of MBP-positive myelin profiles was significantly lower in cultures stimulated at $0.1 \mathrm{~Hz}$. ${ }^{* *} p<0.001$ versus $0 \mathrm{~Hz} ; p<0.02$ ANOVA on $0,0.1$, and $1 \mathrm{~Hz}$, respectively; $n=44$ experiments. $H$, The total number of Schwann cells was not significantly different in stimulated or unstimulated cultures, indicating an inhibitory effect on the myelination process. Scale bars, $50 \mu \mathrm{m}$. 


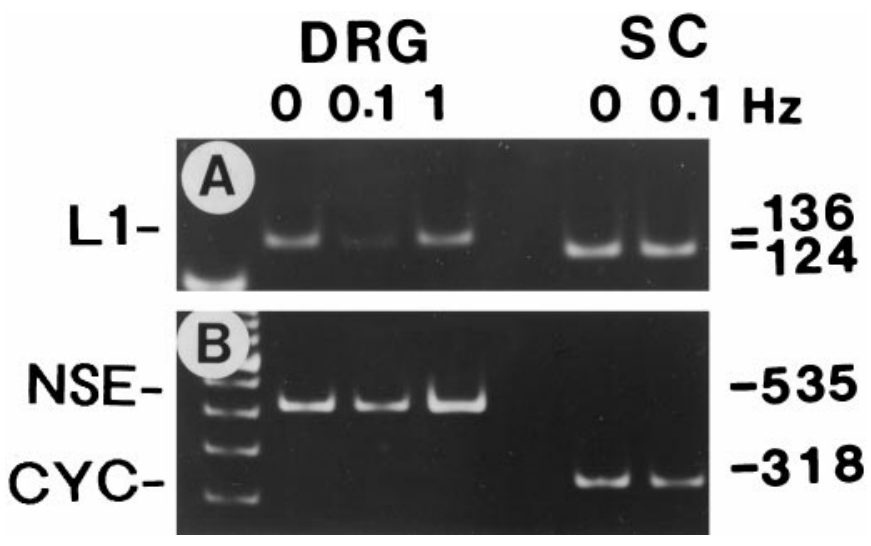

Figure 4. A, L1 mRNA levels were compared in DRG neurons and Schwann cells $(S C)$ using RT-PCR. Stimulation at a frequency of $0.1 \mathrm{~Hz}$ for $5 \mathrm{~d}$ significantly lowered L1 expression in DRG neurons (136 bp PCR product, lane 1 vs lane 2), but stimulation at $1 \mathrm{~Hz}$ had no effect on $\mathrm{L} 1$ levels (lane 3 vs lane 1). Schwann cells express a short-splice isoform of L1 mRNA (Takeda et al., 1996) (124 bp PCR product), which was not detected in these DRG cultures. Stimulation of cultures containing only Schwann cells failed to alter their L1 expression level (lane 4 vs lane 5). B, L1 mRNA levels were normalized to neuron-specific enolase (NSE) mRNA levels in DRG cultures and cyclophilin $(C Y C)$ in Schwann cell cultures.

of a calcium-independent CAM may be involved in inhibition of myelination on axons firing at $0.1 \mathrm{~Hz}$. It has been shown previously that mRNA expression of the calcium-independent CAM L1 in mouse DRG neurons is downregulated 13-fold, $5 \mathrm{~d}$ after stimulating axons at $0.1 \mathrm{~Hz}$ (Itoh et al., 1995b). Levels of L1 protein were reduced $50 \%$ (Itoh et al., 1995b), a magnitude that would be expected to reduce L1-mediated adhesion by 30 -fold (Hoffman and Edelman, 1983). Although a number of secreted or cell surface molecules might contribute to the reduced adhesion and myelination by Schwann cells after stimulation at $0.1 \mathrm{~Hz}$, the correlation with frequencies of stimulation that lower L1 expression in DRG neurons suggests involvement of this cell adhesion molecule (Fig. 4). L1 levels remain high in DRG neurons firing at $1 \mathrm{~Hz}$ (Itoh et al., 1995b), a frequency of stimulation that did not affect myelination. Antibodies against L1 have been shown to block the initiation step in myelination of DRG axons by Schwann cells in culture (Wood et al., 1990), providing causal support for the correlation between the frequencies of stimulation that reduce axonal L1 expression and inhibition of myelination. Also, antibodies against L1 inhibit Schwann cell adhesion to DRG axons (Seilheimer and Schachner, 1988), consistent with the results of the acute adhesion experiments performed in calciumfree medium in the present study.

When stimulation was performed under conditions that block the downregulation of L1, stimulation had no effect on myelination. Nerve growth factor has been shown to upregulate L1 expression in cultured PC12 cells (McGuire and Greene, 1978), by acting through the low-affinity NGF receptor (Itoh et al., 1995a). We observe a similar upregulation of L1 mRNA in DRG cultures treated with NGF at concentrations high enough to activate the low-affinity receptor $(50-200 \mathrm{ng} / \mathrm{ml})$, and this can be used to prevent the decrease in L1 produced by $0.1 \mathrm{~Hz}$ stimulation (Fig. 5). Stimulation at $0.1 \mathrm{~Hz}$ had no effect on myelination when NGF treatment $(50 \mathrm{ng} / \mathrm{ml})$ was used to prevent the activitydependent reduction in L1 (Fig. 5). The number of Schwann cells was not affected by stimulation in the presence of NGF (503 cells/field vs 517 for 0 and $0.1 \mathrm{~Hz}$, respectively; $n=11$ experi-
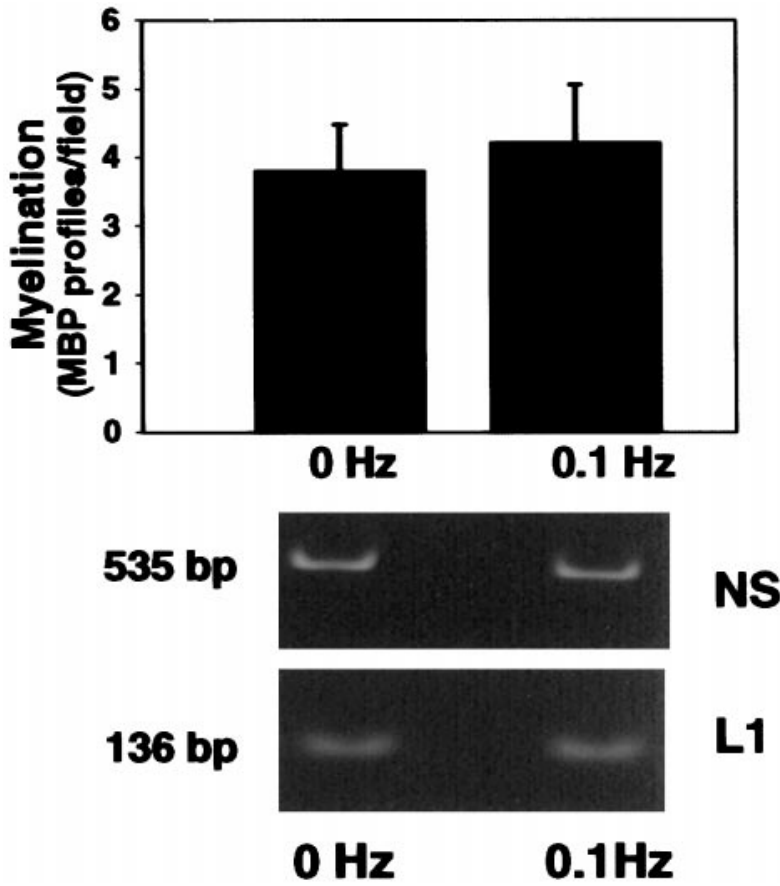

Figure 5. Stimulation at $0.1 \mathrm{~Hz}$ had no effect on myelination when the stimulus-induced change in L1 levels was blocked by adding NGF. Top panel, The number of MBP-positive myelin profiles was not significantly different in cultures stimulated at $0.1 \mathrm{~Hz}$ compared with unstimulated controls in the presence of $50 \mathrm{ng} / \mathrm{ml}$ NGF. Bottom panel, The downregulation of L1 mRNA (136 bp) levels produced by $0.1 \mathrm{~Hz}$ stimulation was prevented by the addition of $50 \mathrm{ng} / \mathrm{ml} \mathrm{NGF}$ during stimulation, which is known to upregulate L1 expression in PC12 cells (McGuire and Greene, 1978) and DRG neurons (Itoh et al., 1995b). NSE mRNA (535 bp) was used as a control for variation in cell density and PCR efficiency.

ments). Previous experiments show that myelination is blocked by antibodies against L1 in DRG/Schwann cell cultures containing $50 \mathrm{ng} / \mathrm{ml}$ NGF (Wood et al., 1990), indicating that NGF does not have a nonspecific effect that would obscure the inhibition of myelination caused by reducing L1-L1 binding.

The effects of action potential firing on Schwann cell adhesion result from activity-dependent regulation of axonal properties as opposed to Schwann cells, because Schwann cells were added after the period of electrical stimulation in the adhesion experiments. Second, intracellular recording has shown that neurons are not stimulated if their axons fail to traverse the barrier between compartments (Fields et al., 1992). Schwann cells would not be depolarized significantly in multicompartment preparations, because they do not traverse the high resistance barrier separating the stimulating electrodes. Finally, L1 mRNA levels did not change in Schwann cells after stimulation at $0.1 \mathrm{~Hz}$ for $5 \mathrm{~d}$ when grown in multicompartment chambers without DRG neurons (Fig. 4).

\section{DISCUSSION}

These data are the first to show that neural impulse activity can influence Schwann cell myelination and that the effects depend on specific frequencies of action potential firing. Regulation of L1 expression on axons firing at appropriate frequencies is a probable molecular mechanism influencing myelinating activity of Schwann cells according to functional impulse activity in the axon. This is suggested by the good correlation between myelination and levels of L1 in axons firing at different frequencies. 
Reduced L1 homophilic binding is sufficient to inhibit myelination, providing causal support for the correlation (Wood et al., 1990). A reduction in L1 expression is necessary for the activitydependent effects on myelination, as shown by blockade of the effect when stimulation is performed under conditions that prevent the reduction in axonal L1 levels.

Action potential activity may alter expression of other molecules on DRG axons, but evidence for their involvement in activity-dependent regulation of myelination is less compelling than for L1. We have recently shown that N-cadherin mRNA expression is reduced in DRG neurons by action potential firing, but the kinetics of the response and the frequency dependence differ from those of L1 and the effects of stimulation on myelination. N-cadherin expression is downregulated rapidly (in $<24 \mathrm{hr}$ ) by $0.1 \mathrm{~Hz}$ and to a greater extent by $1 \mathrm{~Hz}$ stimulation (Itoh et al., 1997), but in the present study myelination was not influenced by stimulation at $1 \mathrm{~Hz}$. This excludes cadherins from having a dominant role in the effects of impulse activity on myelination, and the reduced adhesion of Schwann cells to stimulated axons in calcium-free medium implicates a calcium-independent CAM in responses to $0.1 \mathrm{~Hz}$ stimulation. NCAM levels are not altered in DRG neurons by either 0.1 or $1 \mathrm{~Hz}$ stimulation (Itoh et al., 1997), and this CAM has not been implicated in the process of initiating myelination in previous studies.

It is unlikely that NGF blocks the stimulus-induced effect on myelination through some activity other than the compensatory increase in L1 expression, because $50 \mathrm{ng} / \mathrm{ml} \mathrm{NGF}$ does not prevent the blockade of myelination by antibodies against L1 in culture (Wood et al., 1990). Our DRG/Schwann cell co-cultures contain physiologically relevant concentrations of NGF without exogenously supplied NGF, which is derived in part from NGF secreted from Schwann cells at a rate of $50 \mathrm{pg} / 10^{6}$ cells $/ \mathrm{hr}$ in culture (Furukawa and Furukawa, 1990). Our measurements of samples taken at the time that myelination is initiated indicate a minimum of 2-4 $\mathrm{ng} / \mathrm{ml} \mathrm{NGF}$ in co-culture medium regardless of stimulation at $0,0.1$, or $1 \mathrm{~Hz}$ (our unpublished observations). This level of NGF is sufficient to sustain some functions that are dependent on the TrkA neurotrophin receptor, but it is not sufficient to upregulate L1 by activation of the low-affinity NGF receptor (Itoh et al., 1995a). The concentration of NGF that DRG neurons would encounter during development in vivo is uncertain, but it is known that neurotrophins are highly regulated temporally and spatially during development. The NGF concentration in adult sciatic nerve is $0.7 \mathrm{ng} / \mathrm{g}$ (Furukawa, 1997).

The results cannot be explained by differences in the number of Schwann cells, because counts showed that the number of Schwann cells was not different in cultures stimulated at $0,0.1$, or $1 \mathrm{~Hz}$. The reduced adhesion between Schwann cells and axons stimulated at $0.1 \mathrm{~Hz}$ helps explain a previous observation that fewer Schwann cells are present on axons $4 \mathrm{~d}$ after plating them on DRG axons that had been stimulated for $5 \mathrm{~d}$ at $0.1 \mathrm{~Hz}$ (Itoh et al., 1995b). However, the present study shows that stimulation at 0.1 or $1 \mathrm{~Hz}$ begun a day after the Schwann cells have formed stable contact with axons allowed early, premyelinating events such as recognition, adhesion, proliferation, and other Schwann cell/axon relations to become well established before axonal L1 expression was reduced by stimulation.

The reduced number of myelinated profiles on axons stimulated at low frequency is most likely a result of inhibition of the initiation phase of myelination. This is consistent with previous antibody blockade experiments demonstrating a requirement for L1-L1 interactions between axons and Schwann cells for initiat- ing myelination of DRG axons in culture (Wood et al., 1990). In those experiments, antibodies were added at the time of ascorbic acid treatment to isolate effects to the induction phase of the myelination process. Similarly, in the present study ascorbic acid was added after $4 \mathrm{~d}$ of stimulation to initiate myelination at a point when L1 levels would have been reduced significantly. Previous experiments have shown that $3-5 \mathrm{~d}$ of stimulation at 0.1 $\mathrm{Hz}$ are required to reduce $\mathrm{L} 1$ expression significantly (Itoh et al., 1997). L1 appears to be less important after initiation of myelination, because L1 disappears from both the axon and Schwann cell soon thereafter (Martini and Schachner, 1986) (Fig. 1C), and other cell adhesion molecules become expressed (Martini, 1994).

The biological significance of these results will require further experiments in vivo. Multiple influences on L1 expression, including access to NGF and neuronal impulse firing pattern, as well as other factors affecting myelination, make it difficult to predict how these findings may apply in vivo. However, a number of conclusions and predictions follow from the in vitro experiments. (1) Contrary to studies in optic nerve (Demerens et al., 1996), action potential activity does not appear to be a requisite trigger for myelination of DRG axons, because myelination was not different in unstimulated control cultures (which are not spontaneously active) and cultures stimulated at $1 \mathrm{~Hz}$. (2) The frequency of impulse activity is an important factor in myelination of an axon, suggesting regulation of Schwann cell functions by the specific frequency of electrical activity in individual axons. (3) The effects of impulse activity can be inhibitory when applied at appropriate frequencies, suggesting that initiation of myelination may be regulated by both positive and negative factors. Myelination in the CNS proceeds through a distinct mechanism and in response to different signals; however, the present results raise the possibility that certain patterns of impulse activity could be inhibitory for myelination in the CNS and that activity-dependent regulation of an L1-like CAM could be involved in regulating myelination by oligodendrocytes in the CNS.

It is important to emphasize that the effects of axonal firing on myelination in vitro depend on appropriate frequencies of neural impulses. Previous experiments have shown that $5 \mathrm{~d}$ of incubation in $\mathrm{KCl}$ does not lower the expression of L1 in DRG axons (Itoh et al., 1995b). Consideration of the frequency-specific effects of action potential activity on myelination may help reconcile some of the apparently contradictory results of previous studies of impulse activity on CNS myelination performed using pharmacological treatments (Collelo et al., 1995; Shrager and Novakovic, 1995; Demerens et al., 1996).

The contrasting effects of 0.1 and $1 \mathrm{~Hz}$ stimulation on myelination in vitro correlate with changes in endogenous firing patterns accompanying premyelinating and myelinating phases of DRG development in utero (Fitzgerald and Fulton, 1992). The frequency of activity that inhibits myelination most closely resembles the activity pattern that develops when the DRG neurons first become spontaneously active in utero. The development of spontaneous impulse activity may signal an important functional or developmental time point in the maturation of a neuron and the formation of an appropriate neural circuit. Axon outgrowth and fasciculation, which occur before the start of spontaneous activity, would be promoted by the high levels of L1 found in unstimulated cultures. Reduced levels of L1 during the period when low-frequency impulse activity begins would be compatible with axon defasciculation and inhibition of myelination during 
this developmental period. Although the appropriate cells required for myelination have become associated with DRG axons, inhibition of myelination at this time point may be advantageous for appropriate innervation and development. The results suggest that low-frequency impulse activity may be one of these factors. A higher-frequency firing $(1 \mathrm{~Hz})$, more characteristic of the myelinating phase of development, does not have an effect on myelination. Different frequencies of impulse activity may have different effects in other types of neurons that have other characteristic firing patterns.

Clearly factors other than activity-dependent regulation of L1 expression must operate to control myelination. Myelination is a complex process, essential for normal conduction, which involves dramatic changes in cell morphology, differentiation, gene expression, and association with other cells. It is reasonable to expect that multiple and redundant factors would be involved in regulating myelination, as illustrated by the compensatory responses that allow myelination of axons in transgenic mice lacking L1 (Dahme et al., 1997) or myelin-associated glycoprotein (Li et al., 1994; Montag et al., 1994; Carenini et al., 1997), both of which are critical cell adhesion molecules for induction of myelination on the basis of antisense (Owens and Bunge, 1991) or antibody (Wood et al., 1990) blockade of these molecules at appropriate developmental stages. The results show that the reduction in L1 levels in DRG axons firing at $0.1 \mathrm{~Hz}$ (Itoh et al., 1995b) is of sufficient magnitude to have a significant effect on myelination when impulse activity lowers L1 levels during the initiation phase of myelination. The link between specific frequencies of functional activity and myelination through changes in axonal expression of L1 suggests important consequences for the structural functional relationship of myelinating axons.

\section{REFERENCES}

Aguayo AJ, Epps J, Charron L, Bray GM (1976) Multipotentiality of Schwann cells in cross-anastomosed and grafted myelinated and unmyelinated nerves: quantitative microscopy and radioautography. Brain Res 104:1-20.

Barres BA, Raff MC (1993) Proliferation of oligodendrocyte precursor cells depends on electrical activity in axons. Nature 361:258-260.

Bunge RP, Bunge MB, Bates M (1989) Movements of the Schwann cell nucleus implicate progression of the inner (axon-related) Schwann cell process during myelination. J Cell Biol 109:273-284.

Carenini S, Montag D, Crener H, Schachner M, Martini R (1997) Absence of the myelin-associated glycoprotein (MAG) and the neural cell adhesion molecule (N-CAM) interferes with the maintenance, but not with the formation of peripheral myelin. Cell Tissue Res 287:3-9.

Carenini S, Montag D, Schachner M, Martini R (1998) MAG-deficient Schwann cells myelinate dorsal root ganglion neurons in culture. Glia 22:213-220.

Chomcynski P, Sacchi N (1987) Single-step method of RNA isolation by acid guanidium thiocyanate-phenol-chloroform extraction. Anal Biochem 162:156-159.

Collelo RJ, Devey LR, Imperato E, Pott U (1995) The chronology of oligodendrocyte differentiation in the rat optic nerve: evidence for a signaling step initiating myelination in the CNS. Neurosci Lett 15:7665-7672.

Dahme M, Bartsch U, Martini R, Anliker B, Schachner M, Mantei N (1997) Disruption of the mouse L1 gene leads to malformations of the nervous system. Nat Genet 17:346-349.

Demerens C, Stankoff B, Logak M, Anglade P, Allinquant B, Couraud F, Zalc B, Lubetzki C (1996) Induction of myelination in the central nervous system by electrical activity. Proc Natl Acad Sci USA 93:9887-9892.

Duncan DJ (1934) A relation between axon diameter and myelination determined by measurement of myelinated spinal root fibers. J Comp Neurol 60:437-472.

Eldridge CF, Bunge MB, Bunge RP, Wood PM (1987) Differentiation of axon-related Schwann cells in vitro. Ascorbic acid regulates basal lamina assembly and myelin formation. J Cell Biol 105:1023-1033.

Fields RD (1998) Effects of ion channel activity on development of DRG neurons. J Neurobiol 37:158-170.

Fields RD, Neale EA, Nelson PG (1990) Effects of patterned electrical activity on neurite outgrowth from mouse sensory neurons. J Neurosci 10:2950-2964.

Fields RD, Yu C, Neale EA, Nelson PG (1992) Chronic electrical stimulation of multicompartment cell cultures. In: Practical electrophysiological methods (Kettenman H, Grantyn R, eds), pp 67-76. New York: Wiley-Liss.

Fitzgerald M (1987) Spontaneous and evoked activity of fetal primary afferents in vivo. Nature 326:603-607.

Fitzgerald M, Fulton B (1992) The physiological properties of developing sensory neurons. In: Sensory neurons (Scott SA, ed), pp 287-306. New York: Oxford UP.

Furukawa S (1997) A sensitive two-site (sandwich) enzyme immunoassay system for measuring nerve growth factor. Nippon Yakurigaku Zasshi. 109:235-241.

Furukawa S, Furukawa Y (1990) Nerve growth factor synthesis and its regulatory mechanisms: an approach to therapeutic induction of nerve growth factor synthesis. Cerebrovasc Brain Metab Rev 2:328-344.

Hasel KW, Sutcliffe JG (1990) Nucleotide sequence of a cDNA coding for mouse cyclophilin. Nucleic Acids Res 18:4019.

Hoffman S, Edelman GM (1983) Kinetics of homophilic binding by embryonic and adult forms of the neural cell adhesion molecule. Proc Natl Acad Sci USA 80:5762-5766.

Itoh K, Brackenbury R, Akeson RA (1995a) Induction of L1 mRNA in PC12 cells by NGF is modulated by cell-cell contact and does not require the high affinity NGF receptor. J Neurosci 15:2504-2512.

Itoh K, Stevens B, Schachner M, Fields RD (1995b) Regulated expression of the neural cell adhesion molecule L1 by specific patterns of neural impulses. Science 270:1369-1372.

Itoh K, Ozaki M, Stevens B, Fields RD (1997) Activity-dependent regulation of N-cadherin in DRG neurons: differential regulation of $\mathrm{N}$-cadherin, NCAM and L1 by distinct patterns of action potentials. J Neurobiol 33:735-748.

Kleitman M, Wood PM, Bunge RP (1991) Tissue culture methods for the study of myelination. In: Culturing nerve cells (Banker G, Goslin K, eds), pp 337-377. Cambridge, MA: MIT.

Li C, Tropak MB, Gerlai R, Clapoff S, Abramow-Newerly W, Trapp B, Peterson A, Roder J (1994) Myelination in the absence of myelinassociated glycoprotein. Nature 369:747-750.

Martini R (1994) Expression and functional roles of neural cell surface molecules and extracellular matrix components during development and regeneration. J Neurocytol 23:1-28.

Martini R, Schachner M (1986) Immunoelectron microscopic localization of neural adhesion molecules (L1, N-CAM, and MAG) and their shared carbohydrate epitope and myelin basic protein in developing sciatic nerve. Cell Biol 103:2439-2448.

McGuire JC, Greene LA (1978) NGF stimulates incorporation of fucose or glucosamine into external glycoprotein in cultured rat PC12 cells. Cell 15:357-365.

Mirsky R, Winter J, Abney E, Pruss RM, Gavrilovic J, Raff MC (1980) Myelin-specific proteins and glycolipids in rat Schwann cells and oligodendrocytes in culture. J Cell Biol 84:483-494.

Montag D, Giese KP, Bartsch U, Martini R, Lang Y, Bluthmann H, Karthigasan J, Kirschner DA, Wintergerst ES, Nave KA (1994) Mice deficient for the myelin-associated glycoprotein show subtle abnormalities in myelin. Neuron 13:229-246.

Moos M, Tacke R, Scherer H, Teplow D, Fruh K, Scachner M (1988) Neural cell adhesion molecule L1 as a member of the immunoglobulin superfamily with binding domains similar to fibronectin. Nature 334:701-703.

Owens GC, Bunge RP (1991) Schwann cells infected with a recombinant retrovirus expressing myelin associated glycoprotein antisense RNA do not form myelin. Neuron 7:565-575.

Sakimura K, Kushiya E, Obinata M, Odani S, Takahashi Y (1985) Molecular cloning and the nucleotide sequence of cDNA for neuron- 
specific enolase messenger RNA of rat brain. Proc Natl Acad Sci USA 82:7453-7457.

Salzer JL, Bunge RP, Glaser L (1980) Studies of Schwann cell proliferation. III Evidence for the surface localization of the neurite mitogen. J Cell Biol 84:767-778.

Seilheimer B, Schachner M (1988) Studies of adhesion molecules mediating interactions between cells of peripheral nervous system indicate a major role for L1 in mediating sensory neuron growth on Schwann cells in culture. J Cell Biol 107:341-351.

Seilheimer B, Persohn E, Schachner M (1989) Antibodies to the L1 adhesion molecule inhibit Schwann cell ensheathment of neurons in vitro. J Cell Biol 109:3095-3101.

Shrager P, Novakovic SD (1995) Control of myelination, axonal growth, and synapse formation in spinal cord explants by ion channels and electrical activity. Brain Res Dev Brain Res 88:68-78.

Takeda Y, Asou H, Murakami Y, Miura M, Kobayashi M, Uyemura K (1996) A nonneuronal isoform of cell adhesion molecule L1: tissuespecific expression and functional analysis. J Neurochem 66:2338-2349.

Webster, HD (1971) The geometry of peripheral myelin sheaths during their formation and growth in rat sciatic nerves. J Cell Biol 48:348-367.

Wood PM, Bunge RP (1975) Evidence that sensory axons are mitogenic for Schwann cells. Nature 256:662-664.

Wood PM, Schachner M, Bunge RP (1990) Inhibition of Schwann cell myelination in vitro by antibody to the L1 adhesion molecule. J Neurosci 10:3635-3645. 